\title{
PENENTUAN PERSEDIAAN OPTIMAL PACKING MATERIAL MENGGUNAKAN METODE FIS MAMDANI PADA PERUSAHAAN TEKSTIL DI JAWA TENGAH
}

\author{
Risa Dista Yudianingrum, Lilik Linawati, Leopoldus Ricky Sasongko \\ Program Studi Matematika Universitas Kristen Satya Wacana \\ e-mail:662016020@student.uksw.edu, lilik.linawati@uksw.edu, leopoldus.sasongko@uksw.edu
}

\begin{abstract}
ABSTRAK
Pengelolaan persediaan merupakan bagian penting dalam perusahaan yang mendukung berlangsungnya proses produksi. Namun dalam pengelolaan persediaan barang, masih ditemukan beberapa persediaan barang yang jumlahnya berlebihan dan ada yang kekurangan. Perlu adanya analisis jumlah pengadaan barang yang dapat menyebabkan jumlah persediaan barang menjadi optimal. Apabila dapat ditentukan jumlah pengadaan barang optimal, maka jumlah persediaan barang juga akan optimal karena jumlah persediaan barang adalah jumlah stok awal barang ditambah jumlah pengadaan barang. Penelitian ini menerapkan Metode FIS (Fuzzy Inference System) Mamdani untuk menentukan jumlah pengadaan barang yang optimal berdasarkan jumlah stok awal barang dan jumlah permintaan barang. Disusun model FIS Mamdani dengan menentukan Himpunan Fuzzy sebagai variabel linguistik pembentuk aturan dalam model persediaan agar dapat menghasilkan jumlah persediaan barang optimal dan memenuhi batas yang diberikan oleh perusahaan. Hasil penelitian pada 4 jenis barang yang dipilih menunjukkan bahwa jumlah pengadaan barang berdasarkan model persediaan FIS Mamdani lebih baik dibandingkan dengan pengadaan real di perusahaan tekstil Jawa Tengah.
\end{abstract}

Kata kunci: FIS Mamdani, General Store, Himpunan Fuzzy, Pengadaan, Persediaan.

\begin{abstract}
Inventory management is an important part of a company that supports the production process. But in the inventory management, there are still number of inventory which are excessive and some are lacking. It is necessary to analyze the amount of procurement that can cause the inventory of goods to be optimal. If the optimal amount of procurement can be determined, then the inventory of goods will also be optimal, because the amount of inventory is the number of initial stock of goods plus the amount of procurement. This research applies the method of Mamdani FIS (Fuzzy Inference System) to determine the optimal number of procurement based on the number of initial stock of goods and the number of demand for goods. The Mamdani Fuzzy Inference model is composed by defining the Fuzzy Set as linguistic variabels forming the rules in the inventory model that can produce the optimal number of inventory and meet the limits given by company. The research results on 4 types of selected goods indicate that the amount of procurement based models Mamdani Fuzzy Inference inventory is more optimal than the real procurement in the textile company in Central Java.
\end{abstract}

Keywords: Mamdani Fuzzy Inference System, General Store, Fuzzy Set, Procurement, Inventory.

\section{PENDAHULUAN}

Pengelolaan persediaan barang atau inventory merupakan salah satu bagian penting dalam proses produksi yang dilakukan oleh suatu perusahaan yang berupa bahan baku, barang setengah jadi, barang jadi, barang-barang untuk keperluan operasi pada produksi, atau barang-barang untuk keperluan suatu proyek [1]. Manajemen persediaan barang sesuai [2] adalah salah satu bagian penting dalam suatu perusahaan yang bergerak di bidang produksi yang berfungsi untuk mengelola persediaan barang sedemikian rupa sehingga diperoleh suatu kondisi seimbang antara biaya untuk pengadaan dan penyimpanan barang.

Salah satu perusahaan tekstil di Jawa Tengah sebagai penghasil benang dan kain juga memerlukan kebutuhan bahan baku ataupun bahan pendukungnya. Bahan pendukung tersebut yang nantinya dibutuhkan unit pengguna untuk kelangsungan produksi. Ketersediaan bahan dan harga jual yang ekonomis sangat diperlukan perusahaan untuk mendorong efektivitas penggunaan bahan oleh pihak perusahaan [3]. Berbagai kriteria 


\section{Risa Dista Yudianingrum, Lilik Linawati, Leopoldus Ricky Sasongko}

akan dipertimbangkan untuk mendapatkan bahan pendukung terbaik dengan harga yang ekonomis [4]. Pada umumnya masih dijumpai jumlah persediaan barang yang belum jelas pengelolaannya seperti terdapat persediaan barang yang terlalu berlimpah, atau terlalu sedikit, bahkan tidak ada persedian. Persediaan barang yang optimal dapat dipengaruhi oleh beberapa faktor, seperti jumlah stok awal, pengadaan barang dan pengeluaran barang. Apabila jumlah stok awal barang sedikit, sedangkan jumlah pengeluaran barang banyak, dan jumlah pengadaan sedikit maka akan mengakibatkan kekurangan persediaan barang (stockout). Selain itu apabila jumlah stok awal barang berlimpah, sedangkan jumlah pengeluaran barang sedikit, dan jumlah pengadaan barang banyak, maka persediaan yang ada akan terlalu berlebihan. Perlu adanya stok pengamanan (Safety Stock) yang ditetapkan oleh gudang, yang berfungsi untuk meminimalisir terjadinya kekurangan/kelebihan persediaan barang. Tujuan pengadaan barang yaitu untuk memperoleh barang yang tepat kualitas, kuantitas, sumber, waktu, dan tempat dengan biaya yang optimal [5].

Dari penjelasan yang sudah diutarakan, maka perlu adanya pengendalian persediaan yang didefinisikan sebagai serangkaian kebijakan pengendalian untuk menentukan tingkat persediaan yang harus dijaga, kapan pengadaan barang dilakukan untuk menambah persediaan. Menurut [6] sistem ini menentukan dan menjamin tersedianya persediaan yang tepat dalam kuantitas dan waktu yang tepat. Fuzzy Inference System merupakan salah satu metode penalaran yang sering digunakan pada bidang eksakta dan sosial untuk menangani masalah-masalah yang sulit didefinisikan dengan menggunakan model matematis. Dalam menangani masalah tersebut, dapat dilakukan dengan cara menetapkan variabel Fuzzy yang dibagi menjadi beberapa variabel linguistik. Dalam penelitian ini akan ditentukan Himpunan Fuzzy dari variabel linguistik pembentuk model persediaan barang packing material di perusahaan tekstil Jawa Tengah berdasarkan metode FIS Mamdani, untuk mendapatkan jumlah pengadaan barang yang optimal berdasarkan jumlah stok awal dan jumlah pengeluaran barang dengan memperhatikan ketentuan persediaan aman yang diberikan oleh perusahaan.

Penelitian tentang penentuan persediaan dengan Metode FIS Mamdani telah dilakukan oleh [7] untuk membuat tingkat persediaan beras dengan baik, sehingga secara global mendapatkan persediaan beras secara merata sesuai dengan pengeluaran yang ada. Selain itu juga telah dilakukan oleh [8] untuk memberikan suatu nilai input Persediaan dan Penjualan untuk mendapatkan suatu nilai output Pembelian. Pada penilitian ini akan digunakan metode FIS Mamdani untuk mencari nilai output atau jumlah pengadaan barang packing material yang akan mengakibatkan jumlah persediaan berada pada batas yang ditentukan oleh perusahaan yaitu maksimal 50\% dari barang yang dikeluarkan dan jumlah stok akhir barang minimal harus 50\% dari barang yang dikeluarkan, sehingga dalam penentuan range pada variabel input dan output harus sesuai.

\section{METODE PENELITIAN \\ Himpunan Fuzzy}

Teori Himpunan Fuzzy merupakan perluasan dari teori himpunan klasik (crisp). Pada teori himpunan klasik, keberadaan suatu elemen pada suatu himpunan A, hanya memiliki 2 kemungkinan yaitu menjadi anggota himpunan A atau bukan anggota himpunan A. Dapat ditulis secara matematis yaitu $\mu_{\mathrm{A}}(\mathrm{x})=1$ jika elemen $x$ menjadi anggota himpunan $\mathrm{A}$ atau $\mu_{\mathrm{A}}(\mathrm{x})=0$ jika elemen $x$ tidak menjadi anggota himpunan $\mathrm{A}$. $\mu_{\mathrm{A}}(\mathrm{x})$ disebut fungsi karakteristik. Misalkan untuk menentukan umur dengan variabel $x$ yaitu menunjukkan umur seseorang, berikut ini variabel $x$ akan dibagi menjadi 3 kategori yaitu Muda $: x<35$ tahun; Parobaya: 35 tahun $\leq x \leq 55$ tahun; Tua : $x>55$ tahun dapat digambarkan seperti pada Gambar 1. 

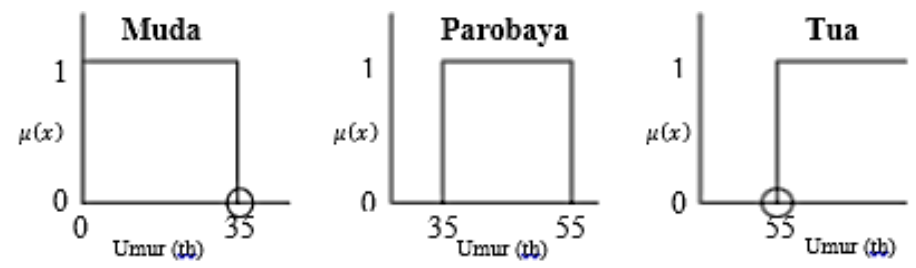

Gambar 1. Himpunan Klasik Muda, Parobaya, dan Tua

Apabila seseorang berumur 35 tahun, maka termasuk dalam kategori "Tidak Muda" dengan $\mu_{\text {Muda }}(35)=0$. Apabila seseorang berumur 35 tahun, maka termasuk dalam kategori "Parobaya" dengan $\mu_{\text {Parobaya }}(35)=1$. Apabila seseorang berumur 35 tahun kurang 1 hari, maka termasuk dalam kategori "Tidak Parobaya" dengan $\mu_{\text {Parobaya }}(35$ th -1 hari $)=0$.

Himpunan Fuzzy (Fuzzy Set) didasarkan pada gagasan untuk memperluas jangkauan fungsi karakteristik, sedemikian hingga fungsi tersebut akan mencakup bilangan real pada interval $[0,1]$. Nilai keanggotaannya menunjukkan bahwa suatu item tidak hanya bernilai benar atau salah. Menurut [9] nilai 0 menunjukkan salah, nilai 1 menunjukkan benar, dan masih ada nilai-nilai yang terletak antara benar dan salah. Dalam Himpunan Fuzzy sebuah nilai crisp dapat terpetakan pada 2 Himpunan Fuzzy yang berbeda. Salah satu cara untuk mendapatkan nilai keanggotaan sesuai [10] adalah melalui pendekatan fungsi pada Gambar 2.

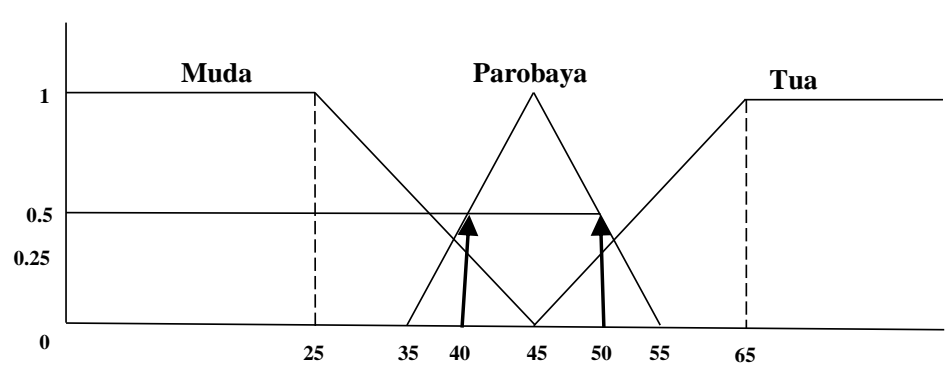

Gambar 2. Himpunan Fuzzy Muda, Parobaya dan Tua

Himpunan Fuzzy dapat dilihat pada Gambar 2 dimana sesorang yang berumur 40 tahun dan 50 tahun memiliki nilai derajat keanggotaan yang sama pada himpunan Parobaya sebesar 0.5 atau dapat ditulis $\mu_{\text {Parobaya }}(40)=0,5$ dan $\mu_{\text {Parobaya }}(50)=0,5$.

\section{Fuzzy Inference System (FIS)}

Fuzzy Inference System (FIS) atau sering disebut dengan IF-THEN rule merupakan cara penarikan kesimpulan dari sekumpulan kaidah Fuzzy yang minimal berisi input FIS (crisp values) dan output FIS (crisp values). Proses FIS disajikan seperti pada Gambar 3.

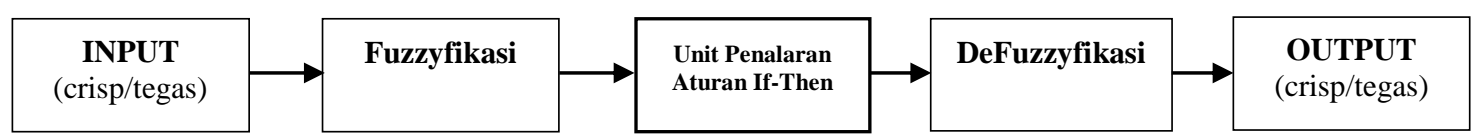

Gambar 3. Skema Fuzzy Inference System

Data masukan berupa nilai crisp yang diubah menjadi Himpunan Fuzzy menggunakan fungsi keanggotaan, disebut proses Fuzzyfikasi. Selanjutnya pada unit penalaran diterapkan aturan-aturan, dimana dapat menggunakan salah satu metode inferensi seperti: Mamdani, Tsukamoto. Keluaran dari unit penalaran adalah data Himpunan Fuzzy, sehingga harus diubah ke bentuk nilai himpunan tegas antara lain dengan menggunakan metode Centroid atau Bisektor sebagai proses Defuzzyfikasi [11]. Terdapat 3 tahap dalam menyelesaikan kasus FIS Mamdani. 
Risa Dista Yudianingrum, Lilik Linawati, Leopoldus Ricky Sasongko

\section{a. Membentuk Himpunan Fuzzy}

Dalam menentukan Himpunan Fuzzy, perlu adanya variabel input dan variabel output yang akan dibagi menjadi satu atau lebih Himpunan Fuzzy disebut Fuzzyfikasi.

\section{b. Membentuk Fungsi Implikasi (Aturan)}

Bentuk umum dari aturan yang digunakan dalam fungsi implikasi adalah IF $\boldsymbol{x}$ is A THEN $\boldsymbol{y}$ is B, dengan $x$ dan $y$ adalah skalar, serta A dan B adalah Himpunan Fuzzy. Fungsi implikasi yang digunakan pada Metode Fuzzy Mamdani adalah Min, sehingga operator Fuzzy yang digunakan adalah AND, seperti:

\section{IF $\left(x_{1}\right.$ is $\left.A_{1}\right)$ AND $\left(x_{2}\right.$ is $\left.A_{2}\right)$ AND $\ldots$ AND $\left(x_{n}\right.$ is $\left.A_{n}\right)$ THEN $y$ is B}

Hasil $\alpha_{\text {predikat }}$ yang mengambil nilai keanggotaan terkecil antara elemen yang berada pada Himpunan Fuzzy, dituliskan pada persamaan (1).

$$
\mu_{\mathrm{A} \cap \mathrm{B}}=\min \left(\mu_{\mathrm{A}}[\mathrm{x}], \mu_{\mathrm{B}}[\mathrm{x}]\right)
$$

Metode yang digunakan pada komposisi aturan adalah metode Max, yaitu mengambil nilai maksimum aturan, kemudian menggunakan nilai tersebut untuk memodifikasi daerah Fuzzy dan mangaplikasikannya ke output dengan menggunakan operator OR. Secara umum dituliskan pada persamaan (2).

$$
\mu_{\mathrm{sf}}\left[\mathrm{x}_{\mathrm{i}}\right]=\max \left(\mu_{\mathrm{sf}}\left[\mathrm{x}_{\mathrm{i}}\right], \mu_{\mathrm{kf}}\left[\mathrm{x}_{\mathrm{i}}\right]\right)
$$

\section{c. Penegasan (Deffuzyfikasi)}

Input dari defuzzyfikasi adalah Himpunan Fuzzy yang diperoleh dari komposisi aturan-aturan Fuzzy, sedangkan output yang dihasilkan merupakan suatu bilangan pada domain Himpunan Fuzzy sesuai dengan [12]:

$$
\begin{aligned}
& z^{*}=\frac{\int_{z} z \mu(z) d z}{\int_{z} \mu(z)} \text { untuk variabel kontinu } \\
& z^{*}=\frac{\sum_{j=1}^{n} z_{j} \mu\left(z_{j}\right)}{\sum_{j=1}^{n} \mu\left(z_{j}\right)} \text { variabel diskrit }
\end{aligned}
$$

\section{Data Penelitian}

Data penelitian yang digunakan pada penelitian ini merupakan data sekunder yang meliputi jumlah stok awal, jumlah permintaan barang, jumlah pengeluaran barang, dan jumlah pengadaan barang (packing material) yang ada di perusahaan serta data yang digunakan yaitu data persediaan 1 tahun yaitu pada Juni 2018 s.d Juni 2019. Data tersebut meliputi 4 barang packing material yang persentasenya sering dikeluarkan/digunakan oleh unit pengguna (Barang A, B, C, dan D).

Perhitungan batas aman pada perusahaan tersebut memiliki standar dengan presentase batas optimal perusahaan untuk semua barang packing material, meliputi:

a. Saldo aman yang harus ada digudang berdasarkan barang yang dikeluarkan, ditunjukkan pada persamaan (5).

$$
\mathrm{SD}=\frac{1}{2} \mathrm{xBK}
$$


c. Persentase batas optimal persediaan barang berdasarkan barang yang dikeluarkan, yaitu:

$$
\mathrm{OP}=\frac{((\mathrm{SA}+\mathrm{PG})-\mathrm{BK})}{\mathrm{BK}}, \text { dengan batas } 50 \% \leq \mathrm{OP} \leq 100 \%
$$

d. Persentase batas optimal saldo barang berdasarkan barang yang dikeluarkan, ditunjukkan pada persamaan (7):

$$
\mathrm{OS}=\frac{(\mathrm{BK}-(\mathrm{SA}+\mathrm{PG}-\mathrm{BK}))}{\mathrm{BK}}, \text { dengan batas } 0 \% \leq \mathrm{OS} \leq 50 \%
$$

Keterangan:

SA merupakan jumlah stok awal barang (unit)

PG merupakan jumlah pengadaan barang (unit)

OP merupakan jumlah optimal persediaan (unit)

BK merupakan jumlah pengeluaran barang (unit)

OS merupakan jumlah optimal saldo barang/Stok Akhir (unit)

SD merupakan batas aman saldo barang/Stok Akhir (unit)

Setelah diketahui batas-batas optimal di atas, langkah selanjutnya akan dihitung pengadaan barang yang optimal sehingga menyebabkan jumlah persediaan dan stok akhir yang optimal pula. Penentuan domain untuk setiap himpunan dilakukan berdasarkan Metode FIS Mamdani, atau seperti pada Gambar 2. Domain harus sesuai sehingga nanti akan diperoleh persentase optimal perusahaan.

Berikut adalah alur perhitungan pengadaan barang optimal dengan menggunakan Metode FIS Mamdani pada Gambar 4, digunakan untuk satu jenis barang. Proses pemodelan dan perhitungan FIS Mamdani dilakukan untuk masing-masing ke-4 jenis barang yang diteliti. Berikut adalah pemodelan dengan Metode FIS Mamdani. Alur perhitungan pada Gambar 3 harus sesuai dengan 3 tahap dalam menyelesaikan kasus FIS Mamdani yang telah dijelaskan sebelumnya.

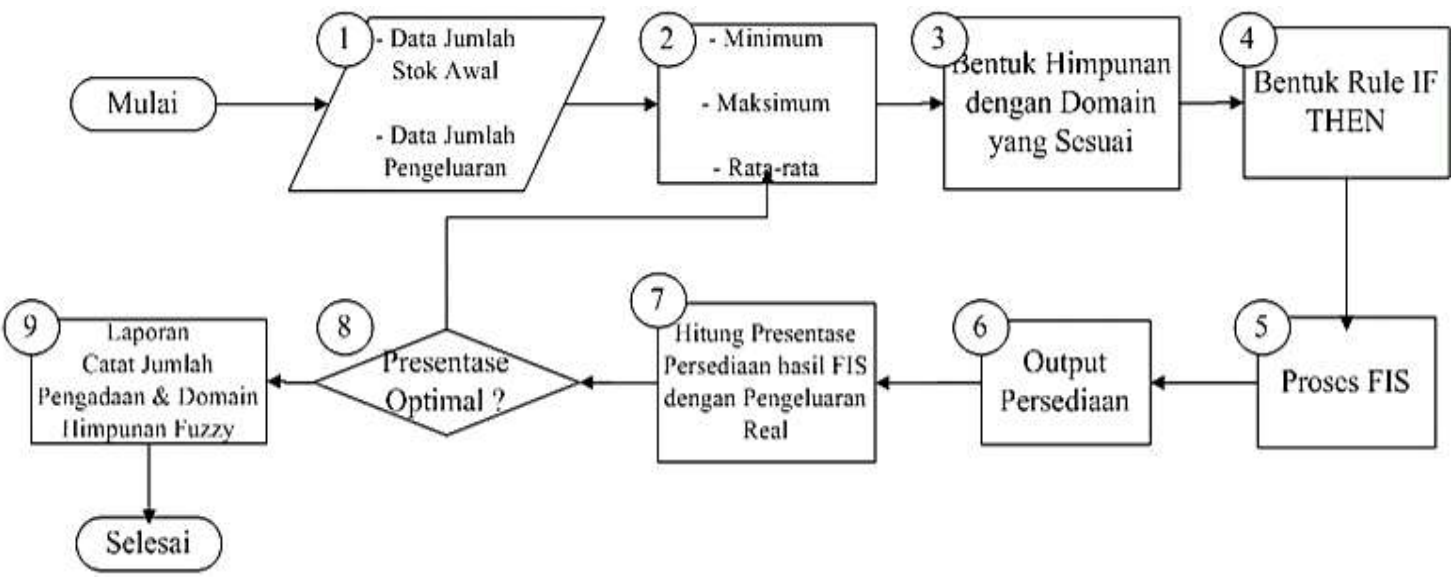

Gambar 4. Skema Perhitungan Jumlah Pengadaan Barang untuk Mendapatkan Persediaan Optimal untuk Satu Jenis Barang

\section{HASIL DAN PEMBAHASAN}

Berdasarkan penerapan FIS Mamdani, digunakan langkah-langkah seperti pada Gambar 4 untuk mendapatkan jumlah pengadaan barang yang optimal. Hasilnya akan diperoleh rentang/batasan domain untuk masing-masing Himpunan Fuzzy yang dibentuk pada setiap variabel yang digunakan. Tabel 1 merupakan Himpunan Fuzzy pada setiap variabel pada 4 Jenis Barang Packing Material yang dipilih. 
Penentuan Persediaan Optimal Packing Material Menggunakan Metode FIS Mamdani pada Perusahaan Tekstil di Jawa Tengah

Risa Dista Yudianingrum, Lilik Linawati, Leopoldus Ricky Sasongko

Tabel 1. Himpunan Fuzzy untuk 4 Jenis Barang Packing Material

\begin{tabular}{cccccc}
\hline \multirow{2}{*}{ Variabel } & \multirow{2}{*}{ Nama Himpunan } & \multicolumn{4}{c}{ Domain Barang (dalam ribuan) } \\
\cline { 2 - 6 } Stok Awal & & $\mathbf{A}$ & $\mathbf{B}$ & $\mathbf{C}$ & $\mathbf{D}$ \\
\cline { 2 - 6 } & Rendah & $0-350$ & $0-400$ & $0-180$ & $0-100$ \\
& Sedang & $300-600$ & $200-650$ & $100-400$ & $50-500$ \\
\cline { 2 - 6 } Pengeluaran & Banyak & $600-1.050$ & $550-730$ & $350-600$ & $400-610$ \\
\cline { 2 - 6 } & Rendah & $0-400$ & $0-250$ & $0-150$ & $0-400$ \\
& Sedang & $350-800$ & $200-520$ & $130-380$ & $300-750$ \\
Pengadaan & Banyak & $650-1.200$ & $400-730$ & $250-570$ & $700-1.150$ \\
\cline { 2 - 6 } & Rendah & $0-150$ & $0-250$ & $0-150$ & $0-600$ \\
& Sedang & $30-540$ & $200-600$ & $100-370$ & $300-1.150$ \\
& Banyak & $420-900$ & $450-700$ & $350-500$ & $950-1.750$ \\
\hline
\end{tabular}

Hasil rentang/batasan domain pada Tabel 1 digunakan sebagai acuan dalam mencari jumlah pengadaan barang packing material. Masing-masing jenis barang memiliki rentang/ domain yang berbeda, dikarenakan karakteristik masing-masing barang berbeda.

Setelah menentukan himpunan fuzzy, maka selanjutnya membentuk aturan/fungsi implikasi yang akan digunakan (berdasarkan data real perusahaan). Dalam pengolahan data ini digunakan Fuzzy Toolbox pada program MATLAB. Fungsi implikasi yang digunakan yaitu sebagai berikut:

[R1] Jika (Stok Awal adalah Rendah) dan (Pengeluaran adalah Rendah) maka (Pengadaan adalah Rendah).

[R2] Jika (Stok Awal adalah Rendah) dan (Pengeluaran adalah Sedang) maka (Pengadaan adalah Banyak).

[R3] Jika (Stok Awal adalah Rendah) dan (Pengeluaran adalah Banyak) maka (Pengadaan adalah Banyak).

[R4] Jika (Stok Awal adalah Sedang) dan (Pengeluaran adalah Rendah) maka (Pengadaan adalah Rendah).

(Sampai aturan ke-17)

[R17] Jika (Stok Awal adalah Banyak) dan (Pengeluaran adalah Sedang) maka (Pengadaan adalah Rendah).

Aturan tersebut digunakan untuk mendapatkan output jumlah pengadaan barangberdasarkan input jumlah stok awal dan jumlah permintaan barang. Rentang/batas domain 4 jenis barang yang telah diketahui pada Tabel 1, akan menghasilkan jumlah pengadaan yang optimal sesuai dengan batas aman yang telah ditetapkan oleh perusahaan. Perhitungan jumlah pengadaan barang dilakukan untuk periode data satu tahun masingmasing barang. Tabel 2 menunjukkan jumlah pengadaan barang real dan pengadaan hasil FIS Mamdani berdasarkan faktor stok awal dan pengeluaran.

Tabel 2. Perbandingan Jumlah Persediaan Real dan FIS Mamdani 4 jenis barang Packing Material

\begin{tabular}{|c|c|c|c|c|c|c|c|c|c|}
\hline \multirow[b]{2}{*}{ Brg } & \multirow[b]{2}{*}{ Bln/Thn } & \multirow[b]{2}{*}{ Stok Awal } & \multirow[b]{2}{*}{ Pengeluaran } & \multicolumn{3}{|c|}{ Real } & \multicolumn{3}{|c|}{ FIS Mamdani } \\
\hline & & & & Pengadaan & Persediaan & Stok Akhir & Pengadaan & $\begin{array}{c}\text { Persediaa } \\
\text { n }\end{array}$ & Stok Akhir \\
\hline \multirow{3}{*}{$\mathbf{A}$} & $06 / 18$ & - & 420.000 & 600.000 & 600.000 & 180.000 & 688.000 & 688.000 & 268.000 \\
\hline & $08 / 18$ & 291.000 & 642.000 & 1.194 .000 & 1.485 .000 & 843.000 & 689.000 & 980.000 & 338.000 \\
\hline & $\vdots$ & $\vdots$ & $\vdots$ & $\vdots$ & $\vdots$ & $\vdots$ & $\vdots$ & $\vdots$ & $\vdots$ \\
\hline \multirow{4}{*}{ B } & $07 / 18$ & 567.232 & 613.872 & 780.064 & 1.347 .296 & 733.424 & 497.000 & 1.064 .232 & 450.360 \\
\hline & $08 / 18$ & 733.424 & 579.600 & 426.384 & 1.159 .808 & 580.208 & 374.000 & 1.107 .424 & 527.824 \\
\hline & $\vdots$ & $\vdots$ & $\vdots$ & $\vdots$ & $\vdots$ & $\vdots$ & $\vdots$ & $\vdots$ & $\vdots$ \\
\hline & $06 / 19$ & 574.968 & 504.000 & 77.616 & 652.584 & 148.584 & 425.000 & 999.968 & 495.968 \\
\hline
\end{tabular}


Lanjutan Tabel 2. Perbandingan Jumlah Persediaan Real dan FIS Mamdani 4 jenis barang Packing Material

\begin{tabular}{|c|c|c|c|c|c|c|c|c|c|}
\hline \multirow{2}{*}{ Brg } & \multirow{2}{*}{ Bln/Thn } & \multirow{2}{*}{ Stok Awal } & \multirow{2}{*}{ Pengeluaran } & \multicolumn{3}{|c|}{ Real } & \multicolumn{3}{|c|}{ FIS Mamdani } \\
\hline & & & & Pengadaan & Persediaan & Stok Akhir & Pengadaan & Persediaan & Stok Akhir \\
\hline \multirow{3}{*}{$\mathbf{C}$} & $07 / 18$ & 599.040 & 480.000 & 326.080 & 925.120 & 445.120 & 240.000 & 839.040 & 359.040 \\
\hline & $\vdots$ & $\vdots$ & $\vdots$ & $\vdots$ & $\vdots$ & $\vdots$ & $\vdots$ & $\vdots$ & $\vdots$ \\
\hline & $06 / 19$ & 186.240 & 135.720 & 215.100 & 401.340 & 265.620 & 65.800 & 252.040 & 116.320 \\
\hline \multirow[t]{3}{*}{ D } & $08 / 18$ & 211.644 & 886.908 & 748.128 & 959.772 & 72.864 & 1.400 .000 & 1.611 .644 & 724.736 \\
\hline & $\vdots$ & $\vdots$ & $\vdots$ & $\vdots$ & $\vdots$ & $\vdots$ & $\vdots$ & $\vdots$ & $\vdots$ \\
\hline & $06 / 19$ & 608.580 & 490.800 & 166.600 & 775.180 & 284.380 & 213.000 & 821.580 & 330.780 \\
\hline & $\begin{array}{l}\text { Rata-rata } \\
\text { Persentase }\end{array}$ & & & & $19 \%$ & $19 \%$ & & $83 \%$ & $83 \%$ \\
\hline
\end{tabular}

Misalkan input data Barang D pada bulan Juni 2019 jika dilihat pada himpunan fuzzy yang telah dibuat, Stok Awal sebanyak 608.580 termasuk kategori "Banyak" dan Permintaan sebanyak 490.800 termasuk kategori "Sedang". Aturan tersebut termasuk pada aturan ke-17 [R17], sehingga pengadaan yang dihasilkan yaitu harus berada pada kategori "Redah" dan hasil yang diperoleh yaitu 166.600.

Dari hasil perhitungan masing-masing barang packing material dapat dilihat hasil rata-rata persentase kesesuaian dengan batas aman perusahaan yaitu, persediaan barang real sebesar 19\% dan persediaan barang hasil perhitungan FIS Mamdani sebesar 83\%. Dari hasil perhitungan tersebut maka perhitungan dengan Metode FIS Mamdani lebih baik (hampir sesuai dengan batas yang ditetapkan perusahaan).

Hasil perbedaan jumlah persediaan real dan FIS Mamdani, dapat dilihat pada grafik perbandingan jumlah persediaan barang berdasarkan data Tabel 2. Grafik tersebut digunakan untuk melihat seberapa optimal data sesuai dengan batas aman yang ditetapkan oleh perusahaan. Berikut ini adalah salah satu grafik perbandingan jumlah persediaan pada Barang D.

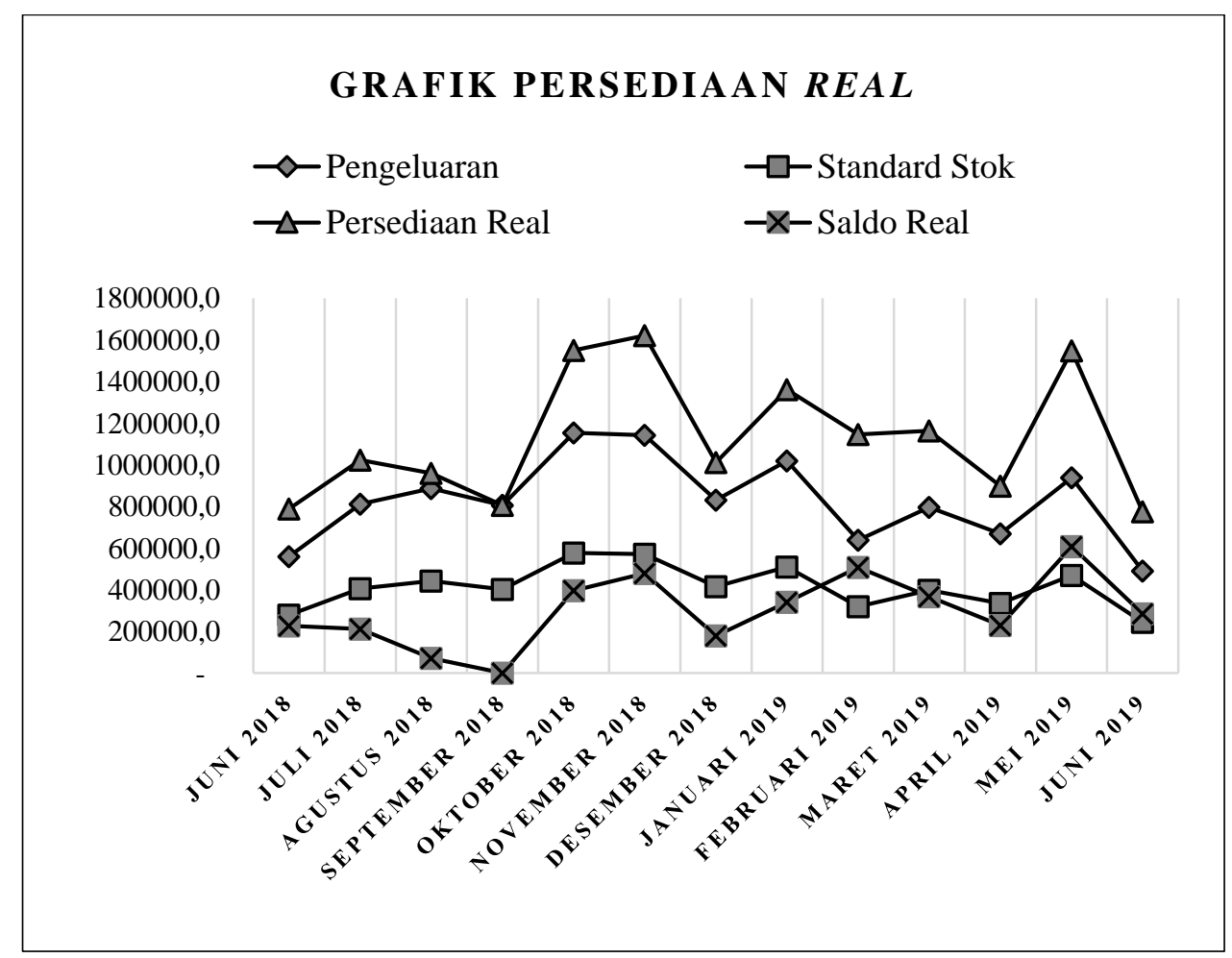

Gambar 5. Grafik Persediaan Real Barang D 


\section{Risa Dista Yudianingrum, Lilik Linawati, Leopoldus Ricky Sasongko}

Menurut Gambar 5, dapat dilihat bahwa jumlah persediaan dan jumlah pengeluaran real Barang D akan mempengaruhi jumlah saldo real. Berdasarkan batas optimal perusahaan, standar stok diperoleh dari $1 / 2$ jumlah pengeluaran Barang D. Diharapkan jumlah saldo real berada di atas standar stok agar tidak terjadi kekurangan persediaan dan tidak melebihi jumlah pengeluaran barang agar persediaan tidak terlalu banyak. Berdasarkan Gambar 5 bahwa jumlah saldo Barang D rata-rata berada di luar batas optimal/standar stok yang ditentukan oleh perusahaan. Hanya terdapat 2 data yang menunjukkan jumlah saldo Barang D yang berada pada standar stok perusahaan yaitu, pada bulan Februari 2019 dan bulan Mei 2019. Selain bulan tersebut saldo real Barang D di luar standar stok perusahaan, yang berarti jumlah barang terlalu sedikit.

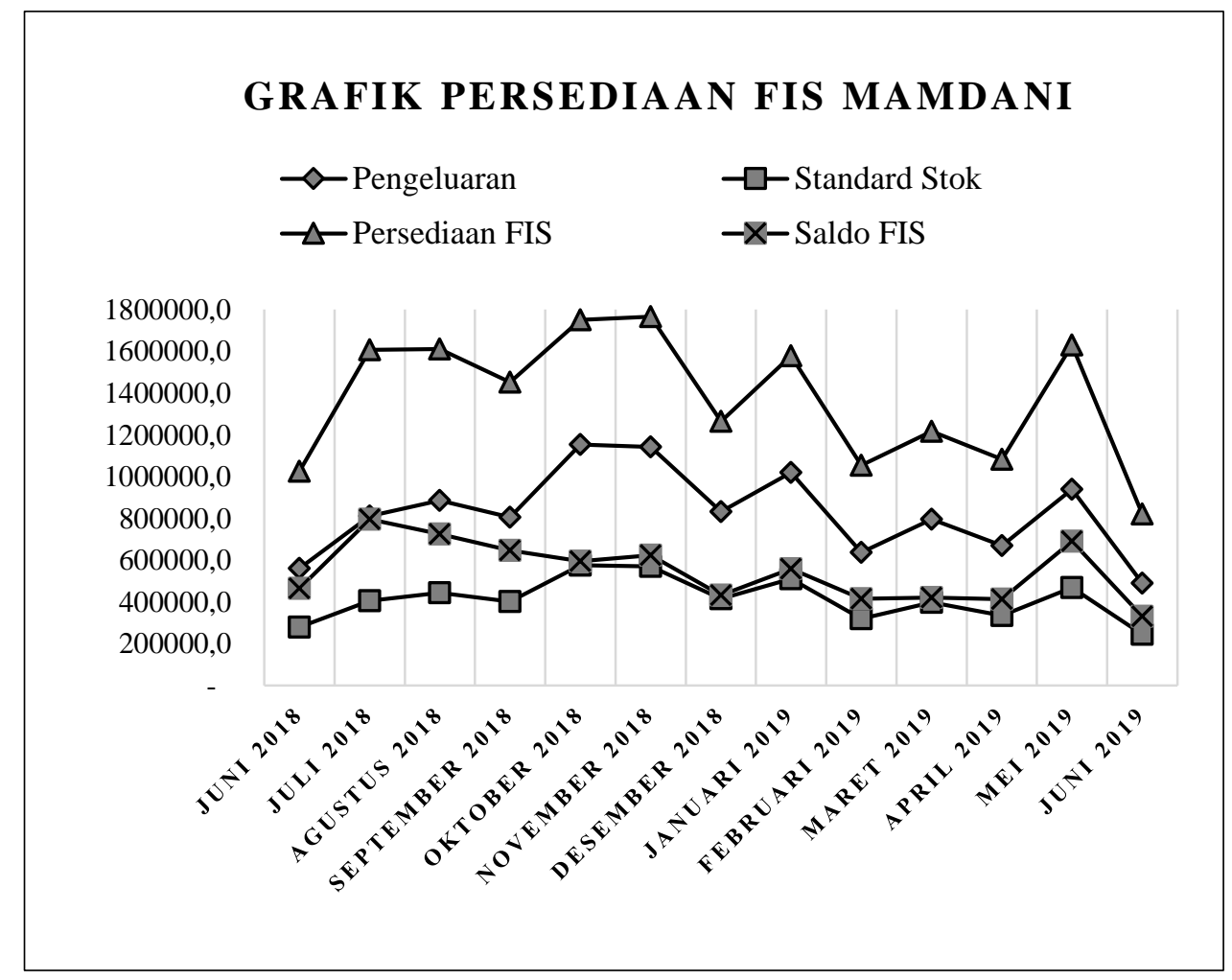

Gambar 6. Grafik Persediaan Perhitungan FIS Mamdani Barang D

Gambar 6 merupakan hasil perhitungan persediaan menggunakan Metode FIS Mamdani sesuai dengan langkah-langkah pada Gambar 4. Apabila penentuan domain sesuai untuk setiap himpunannya maka akan diperoleh hasil saldo Barang d berada di atas standar stok barang. hal tersebut juga akan berpengaruh pada jumlah persediaan barang tidak terlampau banyak atau sedikit. Dapat dilihat bahwa seluruh data pada persediaan 1 tahun berada pada batas optimal perusahaan.

Dari grafik perbandingan pada Gambar 5 dan Gambar 6, dapat dilihat bahwa jumlah persediaan real dan jumlah persediaan FIS Mamdani menunjukkan hasil yang sangat berbeda. Dimana jumlah persediaan real masih terlihat bahwa jumlah persediaan masih berada di luar batas aman perusahaan, sedangkan hasil FIS Mamdani rata-rata berada di batas aman yang telah ditentukan oleh perusahaan.

\section{KESIMPULAN}

Penentuan jumlah pengadaan barang pada 4 jenis barang packing material berdasarkan jumlah stok awal dan jumlah pengeluaran barang menggunakan Metode FIS Mamdani, dapat menghasilkan model persediaan yang sesuai dengan batas yang ditentukan 
oleh perusahaan. Hasil perhitungan jumlah persediaan berdasarkan FIS Mamdani menunjukkan hasil yang lebih baik dibandingkan dengan jumlah persediaan real yang dilakukan oleh perusahaan. Model persediaan FIS Mamdani dapat digunakan untuk menentukan jumlah pengadaan barang yang optimal bagi perusahaan. Dalam penelitian ini masih menganalis perbedaan jumlah pengadaan barang berdasarkan jumlah stok barang, jumlah pengeluaran real dan hasil FIS Mamdani. Disarankan menggunakan metode peramalan untuk meramalkan jumlah permintaan barang pada bulan berikutnya dan dapat dihitung jumlah pengadaan barang pada bulan berikutnya.

\section{DAFTAR PUSTAKA}

[1] R. E. Indarjit dan R. Djokopranoto. Manajemen Persediaan Barang Umum dan Suku Cadang untuk Keperluan Pemeliharaan, Perbaikan, dan Operasi. Jakarta: PT. Gramedia Widiasarana, 2003.

[2] B. F. Rambitan, J. S. B. Sumarauw, dan A. H. Jan. 2018. Analisis Penerapan Manajemen Persediaan Pada CV. Indospice Manado. EMBA, vol. 6, no.3, hal. 14481457.

[3] C. O. Doaly, P. Moengin, dan G. Chandiawan, 2019. PEMILIHAN MULTIKRITERIA PEMASOK DEPARTMENT STORE MENGGUNAKAN METODE FUZZY AHP DAN TOPSIS. J. Ilm. Tek. Ind., vol.7, no.1, hal. 70-78.

[4] W. Kosasih, V. Y. Triyani, dan C. O. D. Ahmad. 2020. MULTI CRITERIA SUPPLIER SELECTION USING A HYBRID FUZZY AHP- TAGUCHI TECHNIQUE: THE CASE OF TEXTILE INDUSTRY. J. Ilm. Tek. Ind., vol. 8, no.2, hal. 79-89.

[5] W. Siahaya, 2014. Manajemen Pengadaan Procurement Management. Bogor: In Media.

[6] A. M. Husein, 2018.Model Manajemen Persediaan berdasarkan Permintaan Menggunakan Teknik Fuzzy Mamdani. Tek. Inform. PRIMA, vol.7, no.2

[7] Masyitha.2018. Menentukan Persediaan Beras Berdasarkan Jumlah Permintaan (Studi kasus: Perusahaan BULOG Regional SUMUT). Skripsi Sarj.

[8] M. Y. T. K. Irsan, M. I. Simbolon, dan I. Pratiwi. Penggunaan Fuzzy Logic \& Metode Mamdani untuk Menghitung Pembelian, Penjualan dan Persediaan. vol.3, no.1, hal. $37-48$.

[9] Sudrajat, 2008. Dasar-Dasar Fuzzy Logic

[10] S. Kusumadewi, S. Hartati, A. Harjoko, dan R. Wardoyo. 2006. Fuzzy Multi-Atribute Decision Making (Fuzzy MADM). Yogyakarta: Graha Ilmu.

[11] H. A. Parhusip dan L. Linawati. 2018 Optimasi Tepat Guna Bagi Data Lokal. Salatiga: Griya Media.

[12] S. Kusumadewi dan Hari Purnomo. 2004. Aplikasi Logika Fuzzy untuk Pendukung Keputusan. Yogyakarta: Graha Ilmu. 